DOI: $10.14746 /$ pi.2021.14.5

\title{
Wiersze o rozmowach, które się nie odbyły
}

\section{Poems about conversations that did not take place}

\author{
|| Barbara Myrdzik
UMCS Lublin
ORCID: 0000-0001-6676-0166
}

\begin{abstract}
The text entitled: "Poems about conversations that did not take place" is an interpretation of two pieces of poetry by Marcin Świetlicki and Ewa Lipska: Talking (at the end of the century) and When we started to talk. Both works deal, in different ways, with the subject of interpersonal communication, in which language and spoken word connect people. Both Ewa Lipska and Marcin Świetlicki see the loss of, not only conversation skills, but social and individual consent to mutual understanding and dialogue. People, once close, become strangers because they have different views and are entangled in the difficult modern times. In individual contacts, they close themselves in their own circles, they do not try to be open to meeting others.
\end{abstract}

Key words: poem, conversation/dialogue, phone call, interpretation, hermeneutics, language

Streszczenie: Tekst zatytułowany Wiersze o rozmowach, które się nie odbyły jest interpretacją dwóch utworów poetyckich autorstwa Marcina Świetlickiego i Ewy Lipskiej: Rozmawianie (na koniec wieku) i Kiedy zaczynaliśmy mówić. Oba utwory w różny dla siebie sposób podejmują temat komunikacji międzyludzkiej, w której język, słowo mówione łączy ludzi. Zarówno Ewa Lipska, jak i Marcin Świetlicki dostrzegają zanik nie tyle umiejętności rozmowy, ile społecznej i indywidualnej zgody na porozumienie, dialog. Ludzie, niegdyś bliscy, stają się obcy, bo mają różne poglądy, są uwikłani we niełatwą współczesność. W kontaktach indywidualnych zamykają się w swoim kręgu, nie starają się być otwartymi na spotkanie $\mathrm{z}$ innym.

Słowa kluczowe: wiersz, rozmowa/dialog, rozmowa telefoniczna, interpretacja, hermeneutyka, język

1.

Poezja jest czymś niezdefiniowalnym, im dłużej myślę o jej definicji, tym bardziej się komplikuje. (...) Jednak poezja tak naprawdę rozpina się pomiędzy próbą poznania i niemożnością poznania.

Adam Zagajewski 
Jednym z określeń, którym sygnowano poezję Marcina Świetlickiego, była „poezja autentyczności”, stająca się swoistą „biografią”, „rekonstrukcją" egzystencji: jej miarą pozostaje konkretne podmiotowe poznanie życia, co stanowi prawdę i drogę poety (Stala 1997, 189-196). Określenie to jednak powodowało dyskusje literackie, zwężające problematykę „autentyczności” jego poezji. Oczywiście nie da się zakwestionować faktu, iż centralnym problemem poezji Świetlickiego pozostaje zagadnienie bio-grafii. Nacisk jednak należy położyć na jej wymiar „graficzny”, przede wszystkim ze względu na przestrzeń, w której poruszać się ma nasza lektura. Nie wolno bowiem zapominać, że istotą omawianych zagadnień jest ich literackość, choć może lepiej byłoby użyć terminu „językowość”, a fakt ten bezpośrednio odsyła nas ku retorycznej naturze przekształceń językowych (Panas 2005, 141151). Przyjrzyjmy się utworowi Rozmawianie (na koniec wieku), którego konstrukcja podmiotu wydaje się w pierwszej chwili biograficzna:

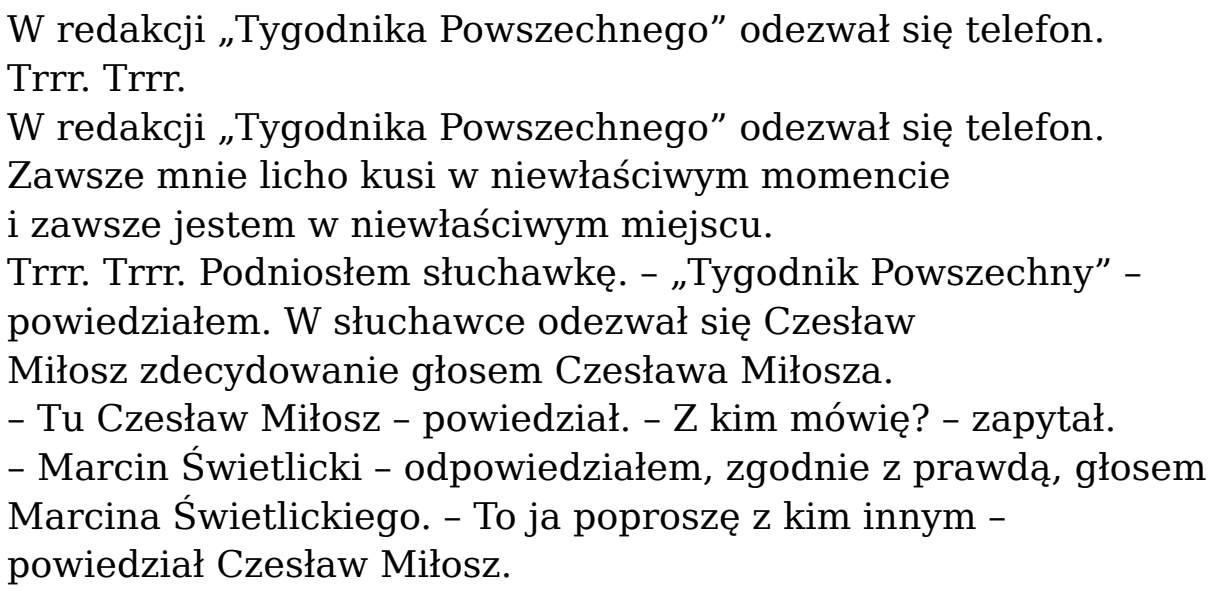

Rozmawiają dwaj poeci, z których jeden jest laureatem Nagrody Nobla, drugi młodym poetą, pełniącym w redakcji „Tygodnika Powszechnego” funkcję sekretarza. Aby rozmowa była udana, osoby biorące w niej udział muszą chcieć rozmawiać i przemawiać językiem docierającym do innego. W wierszu Marcina Świetlickiego nie dochodzi jednak do rozmowy. Można powiedzieć za Gadamerem, że rozmówcy mówią tym samym językiem, tj. odczytują nie tylko poszczególne znaczenia znaków językowych, ale znaczenia nie odnoszą do siebie.

$\mathrm{Na}$ wielość procesów przebiegających w rozmowie zwracał uwagę Hans-Georg Gadamer, który na pytanie - Co się dzieje w rozmowie? - odpowiadał, że nie może dać odpowiedzi na to pytanie żadna teoria, której założeniem byłoby, że jest ona sama ostatnim słowem. Krzysztof Michalski tak interpretuje myśli filozofa:

Jeśli międzyludzka komunikacja jest w istocie nieskończona rozmową, w której - i nigdzie indziej - ciągle na nowo tworzy się sens świata, filozofia - refleksja nad tą rozmową - nie może zakładać, że ów sens jest gotowy (Michalski 2000, 17). 
Bo świat przeżyć i odczuć drugiego człowieka jest niepowtarzalny, zawsze uczasowiony, może znacznie różnić się od naszego, jak jego styl życia, poglądy, kultura i utrwalone przesądy itd.

Aby rozmowa była udana, osoby biorące w niej udział muszą chcieć rozmawiać i przemawiać językiem docierającym do innego. $W$ wierszu Marcina Świetlickiego nie dochodzi do rozmowy. Może wyraża bunt przeciw tradycji? A może jest jeszcze o czymś innym? Wymiana zdań w wierszu nie jest dialogiem w sensie hermeneutycznym, który powinien być porozumiewaniem się ludzi ze sobą, gdyż sens świata ujawniający się w języku nie da się wypowiedzieć w monologu, wymaga komunikacji, w której wychodzi na jaw, że coś rozumie się tak lub inaczej.

Świetlicki tworzy rozmowę, która jest zaskakująco banalna, budząca pytania o jej gatunkową tożsamość. Czy to żart poetycki, który przypomina zabawne anegdoty powtarzane $\mathrm{w}$ towarzystwie? Taki wniosek ma $\mathrm{z}$ pewnością rację bytu, ale zatrzymuje się na progu dosłowności. Wiersz tworzy pełną powtórzeń ironiczną anegdotę o rozmawianiu, które nie było rozmową. Użyty w tytule rzeczownik odczasownikowy (gerundium), sygnalizuje czynność uogólnioną, wykraczającą poza konkretną rozmowę, która najczęściej odbywa się twarzą w twarz lub za pośrednictwem wybranego medium. Zatem Rozmawianie... to opis krótkiej wymiany zdań, ograniczającej się do przedstawienia się sobie rozmówców. Wielki poeta Czesław Miłosz rozpoczyna rozmowę telefoniczną z nieznanym sobie Marcinem Świetlickim i nie zadaje pytania, kim on jest i co robi w „Tygodniku Powszechnym”. Na dodatek nie ma zamiaru go poznawać. Przedstawiający wynik tej rozmowy podmiot utworu i zarazem drugi bohater tekstu komentuje sytuację: „Zawsze mnie licho kusi w niewłaściwym momencie / i zawsze jestem w niewłaściwym miejscu". Uwaga ta staje się wyraźną, autoironiczną interpretacją, ale także komentarzem do roli rozmowy w sferze emocjonalnej człowieka. Po co było podnosić słuchawkę telefonu? No, po co? By narazić się na przykrość? Komentujący zdarzenie nie jest zdystansowany, wie, że wielki poeta dzwoni do redakcji tygodnika, oczekując, że telefon odbierze ktoś mu znany a nie korektor redakcyjny i poeta, o którym możliwe, że nic nie wie. „To ja poproszę z kim innym - / powiedział Czesław Miłosz". Nawet nie z kimś „konkretnym” innym, tylko z anonimowym innym. Zabrzmiało to lekceważąco, choć - jak wolno sądzić - nie miało. Obaj rozmówcy mówili swoimi głosami, pozwalającymi na identyfikację osób, ale tylko Marcin Świetlicki znał głos swojego rozmówcy, Wielkiego Poety. Właściwości głosu mówiącego wpływają na atmosferę komunikacji. Wypowiadane w rozmowie słowa mają zarówno werbalne, jak i niewerbalne znaczenie. Część niewerbalna jest trudniejsza do kontrolowania, więc jest bardziej autentyczna. Można dowiedzieć się wiele o tym, co czuje druga osoba, uważnie wsłuchując się $\mathrm{w}$ ton głosu. Wiele problemów komunikacyjnych, nieporozumień ma swoje źródła w metakomunikatach - informacjach, które przekazywane są na poziomie uczuć (np. brzmienie głosu, akcent itd.). Z wiersza Rozmawianie 
(na koniec wieku) dowiadujemy się więcej o odczuciach jednego rozmówcy, drugiego - można się domyślać.

Marcin Świetlicki we wstępie do wydanych w 2011 roku wierszy napisał: „Poezję robi się z „antymaterii”. Poezję robi się przeciw. Przeciw instytucji jakkolwiek by się nie nazywała. Przeciw każdej" (Świetlicki 2011, 5). Odnosząc przywołaną wypowiedź, która jest rodzajem minimanifestu, do cytowanego wiersza, można zapytać: przeciwko czemu skierowany jest utwór Rozmawianie (na koniec wieku)? Nawiasowa część tytułu utworu wyraźnie odsyła do wiersza Kazimierza Przerwy-Tetmajera Koniec wieku XIX oraz podkreśla społecznie akceptowane przekonanie o końcu wieku jako zakończeniu pewnej epoki. Jaka to była epoka? Pomijając wszelkie szczegóły, można stwierdzić, iż wówczas ludzie ze sobą chętniej rozmawiali, prowadzili dysputy, spotykali się po to, by recytować wiersze z ważnej okazji, śpiewać piosenki itd. Rozmowa nie miała być polemicznym dyskursem, lecz z jej przebiegu wyłaniał się wspólny aspekt tego, czego ona dotyczyła. Udana rozmowa przejawia się w tym, że nie można powrócić do wyjściowych kontrowersji, gdyż narodziła wspólną wykładnię świata, która umożliwia społeczną etykę i solidarność. Uchwycić trzeba retoryczną zasadność poglądu rozmówcy, abyśmy mogli się zgodzić co do danej sprawy. Jego pogląd odnosimy więc nie do niego, lecz do własnych przekonań i zapatrywań.

Utwór Marcina Świetlickiego odczytuję jako wypowiedź przeciwko obojętności ludzi wobec innych? Może też wyraża bunt przeciw tradycji, która hierarchizowała „miejsce wielkich” w historii literatury. O braku wrażliwości? Także o tym, by w niespodziewanej rozmowie wysłuchać drugiego? $\mathrm{Na}$ przykład o tym, że „granica między gestem poetyckim i egzystencjalnym może być i bywa zatarta" (Stala 1997).

2.

Wierzę, że każdy dobry wiersz jest po prostu listem do drugiego człowieka. Moja radość nie miała granic, kiedy u jednego z najbardziej wyrafinowanych poetów XX wieku, Paula Celana, znalazłem dokładnie taką samą myśl: że wiersz jest podaniem ręki drugiemu człowiekowi, rozmową. Ja się tego trzymam .

Piotr Matywiecki

Czytając wiersz Ewy Lipskiej Kiedy próbowaliśmy ze soba rozmawiać, natrafiamy na poetycką diagnozę skonfliktowanego społeczeństwa:

Kiedy próbowaliśmy ze sobą rozmawiać

okazało się

że mamy różne języki.

Kiedy zaczynaliśmy mówić

wspólnym językiem 
odebrano nam mowę.

Kiedy schodziliśmy ze wzgórz

łączyły nas już tylko

cienie umarłych.

(z tomu Przechowalnie ciemności, 1985)

Sytuacja opisana w utworze wskazuje na trzy ważne momenty zachodzące w stosunkach międzyludzkich: nieudana próba rozmowy z powodu braku poczucia wspólnoty; wypracowanie wspólnego języka i potencjalna możliwość rozmowy, do której jednak nie doszło z powodu (znowu!) utraty wspólnego języka. Nasuwa się tu skojarzenie z biblijnym motywem Wieży Babel, chociaż w utworze poetki nie ma explicite wyrażonych przytoczeń, są jednak tropy wskazujące na ten mit:

Kiedy zaczynaliśmy mówić

wspólnym językiem

odebrano nam mowę.

W Biblii czytamy:

1 Cała ziemia miała jedną mowę i jeden język. 2 A, gdy wędrowali ze wschodu, napotkali równinę w kraju Szinear i tam zamieszkali. 3 I mówili jeden do drugiego: Chodźmy, wyrabiajmy cegłę i wypalajmy ją w ogniu. I tak mieli cegłę zamiast kamieni, mieli też smołę zamiast zaprawy murarskiej. 4 Wtedy rzekli: Chodźmy, zbudujmy sobie miasto i wieżę, której wierzchołek sięgnie nieba, i uczynimy sobie znak, abyśmy się nie rozproszyli po powierzchni całej ziemi. 5 A Pan zstąpił z nieba, by zobaczyć miasto i wieżę, które budowali ludzie. 6 I rzekł: Są oni jednym ludem i wszyscy mają jedną mowę, i to jest przyczyną, że zaczęli budować. Zatem w przyszłości nic nie będzie dla nich niemożliwe, cokolwiek zamierzą uczynić. 7 Zejdźmy więc i pomieszajmy tam ich język, by jeden nie rozumiał drugiego! 8 I Pan rozproszył ich stamtąd po powierzchni całej ziemi tak, że nie dokończyli budowy tego miasta. 9 Dlatego to nazwano je Babel, tam bowiem Pan pomieszał mowę mieszkańców całej ziemi; stamtąd też Pan rozproszył ich po powierzchni całej ziemi ${ }^{1}$.

Historia wieży babilońskiej świadczy o fundamentalnym znaczeniu języka dla ludzkiego życia. W narracji o budowie Wieży Babel i pomieszaniu języków zawarta jest obrazowa odpowiedź na pytanie o powstanie języków i przyczyny obcości, a także niezgody ludzi wobec siebie. Dramat kary, która spadła na budowniczych Wieży, miał dwa akty: rozproszenie, spowodowane duchem niezgody oraz pomieszanie języków. Niezgoda nie pozwoliła na dokończenie budowy wieży i na wspólne przebywanie mieszkańców miasta²

Motyw biblijny Wieży Babel w dziejach kultury był wielokrotnie wykorzystywany przez poetów, malarzy, teologów, językoznawców³ ${ }^{3}$ Przykładowo można wymienić następujących artystów tworzących dzieła inspirowane motywem biblijnym: Wieże Babel Breugela Starszego, Boscha, Borgesa,

\footnotetext{
${ }^{1}$ Księga Rodzaju 11,1-9, Biblia Tysiaclecia, Poznań - Warszawa, 1982, s. 32.

${ }^{2}$ W Nowym Testamencie zesłanie Ducha Świętego w dzień Zielonych Świąt stało się przez dar języków zapowiedzią eschatologicznej jedności wszystkich ludzi w końcowej fazie królestwa mesjańskiego.

3 Np. P. Breugel, W. Szymborska, J. Kaczmarski, I. Strawiński kantata „Babel”, „Metropolis” F. Langa, J. Dudy „Babel-2” i inne.
} 
psychicznej (świadomościowej, duchowej), brak wspólnoty określonych przekonań, uczuć i akceptowanych wartości. Narzucając na opisany świat relacje czasowe, podkreśla, że czas, poza językiem, zakreśla horyzont bycia z innymi. Autorka trzykrotnie wyraża to powtórzeniem zaimka „kiedy”. „Kiedy” to nie „Kiedyś” - co sugerowałoby przeszłość - tutaj następuje powiązanie czasu z ruchem, a także z dokonującymi się zmianami historyczno-społecznymi. I chociaż brak jest w wierszu datowania tego „kiedy”, możemy domyślać się (data wydania tomu poezji - 1985), że utwór odwołuje się do rzeczywistości lat 80. w Polsce. Może do stanu wojennego i jego konsekwencji polityczno-społecznych? Jest to jedna z możliwości interpretacji utworu, której nie będę rozwijać. Można też odczytać wiersz w perspektywie uniwersalnej, wówczas dostrzeżemy w nim diagnozą naszej współczesności, w której kłamstwo i przemoc stało się narzędziem polityki, pomieszania pojęć języka i skłócenia ze sobą społeczeństwa.

Byt człowieka polega na wikłaniu się w poszukiwaniu znaczeń wieloznaczności. W tej wieloznaczności ma swój udział również słowo poetyckie. Słowo poetyckie jest także mityczne, tzn. uwierzytelnia je tylko to, co w nim zawarto. Wieloznaczność słowa poetyckiego odpowiada wieloznaczności ludzkiego bytu w ogóle i stąd wynika jego szczególna godność (Gadamer 1977, 305).

Utwór poetycki traktowany jako rozmowa rodzi się z pewnej szczególnej wrażliwości i z potrzeby wyrażenia w sposób nowy stosunku do świata i do nas samych. Wiersz Ewy Lipskiej w sposób bardzo oszczędny zarysowuje sytuację, nie mówi wprost o przyczynach nawiązania porozumienia i dramacie jego zerwania. Są w życiu takie sytuacje, w których mówimy: Odebrało mi mowę! Język zawodzi w momentach zaskoczenia, zdumienia, czyli pod wpływem silnych emocji. Jednak zdanie: odebrano nam mowę, wskazuje na zewnętrzną przemoc wobec zbiorowości. Czas indywidualny i społeczny dzieje się tu równocześnie, ma swoją przyczynę i skutek. Oddziaływanie czasu obiektywnego poetka sygnalizuje zmianami w języku, który jest w utworze określany wyrażeniami: mamy różne języki; Kiedy zaczynaliśmy mówić/ odebrano nam mowę. Język nie może już stworzyć wspólnoty, gdyż ludzie nie są w stanie ze sobą rozmawiać, zapomnieli o wszystkim, co ich łączyło, co było wspólną mową. Można zatem założyć, że utwór przedstawia też poetycką diagnozę pokolenia (my), którego doświadczenia okazały się dla niego klęską. To, co zostało ze wspólnoty, dotyczy tylko pamięci o tych, którzy przeminęli, znaleźli się „po drugiej stronie świec" (S. Grochowiak).

Kiedy schodziliśmy ze wzgórz

łączyły nas już tylko

cienie umarłych.

W przywołanym fragmencie pojawiają się motywy wzgórza i pamięci. Wzgórze jako przestrzeń nie istnieje w wierszu tylko jako obiektywna część rzeczywistości, której wszyscy nadajemy ten sam sens i w ten sam sposób 
Białoszewskiego, Herberta. Artyści w swoich dziełach różnie interpretowali tę historię, kładąc najczęściej akcenty na niemożność rozmowy, podkreślali obcość i negatywne skutki utraty wspólnego języka, a także wyrażali pragnienie powrotu do „języka rajskiego”. Pierwszy człowiek, nadając bytom imiona, nazwy, stawał się medium „czystego języka”, będącego gwarantem jedności Stworzenia tudzież podstawą wszelkiego prawdziwego poznania. Tak oto Bóg, udzielając Adamowi słowa, uczynił zeń swego tłumacza (Benjamin 1996).

Michel Foucault w Słowach i rzeczach przedstawił poglądową charakterystykę tego języka:

W swoim pierwotnym kształcie, kiedy darował go ludziom sam Bóg, język był absolutnie pewnym i przezroczystym znakiem rzeczy, ponieważje odwzorowywał. Imiona do rzeczy, na które wskazują, przylegały tak samo, jak siła wpisuje się w ciało lwa, królowanie we wzrok orła, jak wpływ planet zaznacza się w zmarszczkach na czole - w postaci podobieństwa. Ta przezroczystość rozpadła się w Babel na pokaranie ludzi. Języki nie pomieszałyby się ze sobą, gdyby od razu nie zatarło się tam odwzorowanie rzeczy, które stanowią rację bytu języka. Wszystkimi językami, jakimi się odtąd posługujemy, mówimy z utraconej głębi podobieństwa, w opuszczonej przez nie przestrzeni (Foucault 2002, 63).

Historia biblijna świadczy o fundamentalnym znaczeniu języka dla ludzkiego życia. Człowiek, działając przeciw Bogu, utracił zdolność posługiwania się językiem Adamowym. Zamiast jednego języka uzyskał ich wiele, ale „zatarło się tam odwzorowanie rzeczy, które stanowią rację bytu języka”. Jednym z najważniejszych symptomów kryzysu nowoczesności jest degradacja i fragmentaryzacja doświadczenia oraz języka. Zdaniem Waltera Benjamina, nie tylko komunikacja potoczna, ale i literatura, a szczególnie poezja, cierpi na kompleks „braku słowa”. Przypisuje on językowi dwie różne funkcje: semiotyczną i mimetyczną. Zadanie odczytywania Księgi natury, języka rzeczy jawi się jako najwyższa forma realizacji „mimetycznego daru", zastąpiona przez konwencjonalne pismo. Świat naszego doświadczenia przesycony jest językiem, w którym skrywają się imiona rzeczy - a naszym zadaniem jest je wydobyć (Benjamin 2011, 5-6).

Człowiek, ucząc się języka, przyswaja sobie istniejący w nim obraz świata, chociaż posługując się językiem, najczęściej nie zwraca uwagi na tę jego ważną funkcję. Język pełni rolę medium, które powoduje, że „świat” dociera do człowieka i tworzy w nim samym „świat” kultury, tradycji; ma zatem zasadniczy wpływ na ludzkie myślenie i poznanie (Gadamer 1967, 146).To, jak człowiek rozumie swój język i swoje doświadczenie, wpływa na jego myślenie i działanie, na jego porozumiewanie się z innymi. Na rozmowę lub jej brak.

Ewa Lipska w wierszu Kiedy zaczynaliśmy mówić kreśli portret pewnej zbiorowości, (użycie zaimka osobowego w l.mn.) zwraca uwagę na zmiany dokonujące się między bohaterami wiersza pod wpływem upływającego czasu ściśle związanego ze zmianami historyczno-społecznymi: zanik więzi 
ją rozumiemy, ale jako wspólnotowe doświadczenie. Odległość oznacza stopień dostępności, a także stopień zainteresowania. Dystans w przestrzeni jest odbiciem emocjonalnej i społecznej odległości. Zanim zapanowała obcość, były wspólne poglądy, zainteresowania, podziwiano te same osoby, ideały, symbolizowane w wierszu przez wzgórza - wzniesienia trochę niższe niż góry, które w kulturze zawsze były kojarzone z przestrzenią wzniosłą, sakralną, mityczną, a także oznaczały: stałość, niewzruszoność, niezłomność, atrybut pokoju, swobody, wzniosłość myśli, transcendencję itd. (Kopaliński 1990, 100-103). Pod wpływem czasu i zmian społecznych nastąpiło różnicowanie społeczeństwa na: „my” i „oni”. Wszystko, co wspólne, zostało utracone, pozostały już tylko „cienie umarłych”, przechowywane w pamięci. Jak można sądzić, jest to już tylko pamięć kulturowa a nie komunikacyjna, która polega na tym, że obraz minionych wydarzeń kształtowany jest poprzez relacje świadków, przekazywane w drodze międzypokoleniowego dialogu. Pamięć kulturowa koncentruje się na takich punktach z przeszłości, które z czasem krystalizują się jako „figury symboliczne” i na których „opiera się nasza pamięć" (Assman 2008). Wówczas pamiętamy to, co nam odpowiada. Stąd wiele postaci z przeszłości, ale także zdarzeń, procesów jest niesprawiedliwie zapomnianych. Jedne są wyidealizowane, inne - źle oceniane. Pamięć kulturowa wyłania się w chwili, gdy pamięć komunikacyjna zaczyna wygasać („cienie”). Razem z odchodzeniem świadków historii upamiętnianie przeszłości zostaje przeniesione w obszar zewnętrzny: rytualny i materialny, ale bez wspólnego języka (Assman 2008).

Wybierając wiersze do opracowania, kierowałam się zarówno podobieństwem tematu, jak i zasadniczą odmiennością formy. Utwór Marcina Świetlickiego sytuuje się wśród zabawnych fraszek, natomiast Ewy Lipskiej zwraca uwagę smutnym nastrojem, problematyką społeczną, której nie można już odwrócić.

\section{Bibliografia:}

Assman Jan, 2008, Pamięć kulturowa. Pismo, zapamiętywanie i polityczna tożsamość w cywilizacjach starożytnych, Kryczyńska-Pham A. (przeł.), Warszawa.

Benjamin Walter, 1996, Narrator. Rozważania o twórczości Mikołaja Leskowa, w: Anioł historii: eseje, szkice, fragmenty, Orłowski H. (wybór i oprac.), Poznań.

Benjamin Walter, 2011, O języku w ogóle i języku człowieka, Lipszyc A. (przeł.), „Literatura na Świecie”, s. 5-6.

Foucault Michel, 2002, Słowa i rzeczy. Archeologia nauk humanistycznych, Komendant T. (przeł.), Gdańsk.

Gadamer Hans-Georg, 1993, Prawda i metoda. Zarys hermeneutyki filozoficznej, Baran B. (przeł.), Kraków.

Gadamer Hans-Georg, 2003, Język i rozumienie, Dehnel P., Sierocka B. (przeł.), Warszawa. 
Gadamer Hans-Georg, 1977, Poezja i interpretacja, Łukasiewicz M. (przeł.), „Pamiętnik Literacki”, z. 4.

Gadamer Hans-Georg, 1967, Die philosopchischen Grundlagen des zwanzigsten Jahrhunders, Kleine Schrieften, Tubingen.

Kopaliński Władysław, 1990, Słownik symboli, Warszawa.

Księga Rodzaju 11,1-9, Biblia Tysiaclecia, 1982, wydanie trzecie poprawione, Poznań - Warszawa.

Michalski Krzysztof, 2000, Gadamer, w: Gadamer H.G., Rozum, słowo, dzieje. Szkice wybrane, Michalski K. (wybrał i wstępem poprzedził), Łukasiewicz M. (przeł.), Warszawa.

Michalski Rafał, 2004, Koncepcja idei języka we wczesnej filozofii Waltera Benjamina, „Filo-Sofija”, 1/4.

Panas Paweł, 2005, Na tropach autora. O poezji Marcina Świetlickiego i nie tylko, „Teksty Drugie”, nr 6, s. 141-151.

Skarga Barbara, 2005, W poszukiwaniu źródłowego czasu, w: Kwintet metafizyczny, Kraków, s. 25-84.

Stala Marian, 1997, Piosenka niekochanego, w: Druga strona. Notatki o poezji współczesnej, Kraków.

Świetlicki Marcin, 2011, Wiersze, Kraków.

Z Piotrem Matywieckim rozmawia Jarosław Mikołajewski https://wyborcza. pl/1,75410,19151733,piotr-matywiecki-wiersz-to-list-do-czlowieka-rozmowa. html.

\section{O Autorce:}

Barbara Myrdzik - prof. dr hab., emerytowana profesor Instytutu Filologii Polskiej UMCS w Lublinie. Autorka ponad 120 artykułów naukowych i metodycznych, a także książek: Poezja Zbigniewa Herberta $w$ recepcji maturzystów (Lublin 1992); Rola hermeneutyki w edukacji polonistycznej (Lublin 1999); Zrozumieć siebie i świat. Szkice i studia o edukacji polonistycznej (Lublin 2006). Współautorka książek: Przestrzenie rzeczywiste i wyobrażone. O roli kulturowego doświadczenia przestrzenności (współaut. I. Morawska, M. Latoch-Zielińska, Lublin 2016); Przestrzenie rzeczywiste i wyobrażone. Metodyczny wielogłos o różnych przestrzeniach (współaut. I. Morawska, M. Latoch-Zielińska, Lublin 2016). 
